\title{
A gestão de processos na análise das atividades de seleções públicas simplificadas: estudo de caso em uma prefeitura
}

\section{RESUMO}

Apresenta um estudo de caso, cujo objetivo foi mapear e analisar processos organizacionais na perspectiva de tornar o serviço público mais ágil, eficiente e focado no usuário. O objeto de estudo foi o processo das seleções públicas simplificadas realizadas por uma Prefeitura, observado segundo a teoria do fluxo de informação. A coleta dos dados combinou observações diretas e o acompanhamento do processo durante o período de outubro a novembro de 2014, e para a representação do fluxo e a descrição dos seus elementos utilizou-se o aplicativo Bizagi Modeler. Os processos seletivos simplificados foram redimensionados em níveis de desempenho e o estudo apontou que é possível decidir com mais objetividade no que se refere à sequência de atividades, à distribuição do trabalho e à previsão do tempo de sua execução.

Palavras-chave: Gestão de Processos. Fluxos de Informação. Processo Seletivo Simplificado.

Marcos Antônio Gomes Falcão Júnior

Bacharel em Gestão da Informação 


\section{INTRODUÇÃO}

É perceptível que gradativamente as organizações públicas vêm sofrendo profundas mudanças, notáveis pelas modificações nas relações sociais e políticas entre os diversos agentes envolvidos. As tecnologias que surgem em ritmo cada vez mais acelerado, e que se tornam disponíveis e essenciais, modificam as relações de trabalho nestas organizações assim como nas organizações privadas.

Tais mudanças representam novas oportunidades de serviços ou novas formas de conduzir serviços antigos. A gestão por processos pode ser considerada uma dessas oportunidades, permitindo às organizações públicas a identificação das melhores práticas para trabalhar e aumentar a satisfação de todos que delas participam. A partir disso, evidencia-se o interesse na aplicação desse método de gestão, que desencadeia o contexto contínuo de renovação pessoal e organizacional no cenário administrativo público, fomentando a inovação e a qualidade nos serviços prestados à população.

Entretanto, os processos têm sido analisados, melhorados e otimizados com mais frequência nas organizações privadas, não sendo tratados com a devida ênfase no setor público. Um dos maiores desafios da administração pública brasileira ainda é de natureza gerencial, fazendo com que se busquem alternativas de gestão focadas em qualidade nos processos internos e orientadas a resultados para o cidadão.

Assim como as empresas privadas, as organizações públicas também precisam superar a visão de gestão unicamente funcional no sentido de quebrar as fronteiras organizacionais internas e, sempre que possível, eliminar tarefas desnecessárias, gargalos, retrabalho e duplicidade de atividades que não agregam valor ao cidadão. Nesse sentido, o âmbito da pesquisa delimitou sua ação em uma Prefeitura da Região Metropolitana do Recife e se concentrou na análise das atividades que compõem seus Processos Seletivos Simplificados. Assim sendo, o seguinte problema refletiu o foco deste estudo: Quais são os aspectos relacionados à gestão dos processos seletivos simplificados que podem ser melhorados?

A gestão de processos se caracteriza como um recurso gerencial importante na busca por eficiência na operacionalização dos serviços públicos, por visar às melhores formas de trabalhar e aumentar a qualidade nos serviços prestados à população. Subjacente à operação de qualquer processo circula um fluxo de informações, permeando todas as suas etapas, transferindo informações nos dois sentidos e em todos os elos.

Assim, este estudo teve como objetivo mapear e analisar processos organizacionais na perspectiva de tornar o serviço público mais ágil, eficiente e focado no usuário. Processo é aqui entendido como um conjunto de atividades realizadas em uma sequência lógica de tarefas, com vistas a oferecer valor a um cliente. No mesmo sentido, assumiu-se que gerenciar um processo é monitorar continuamente seu desempenho, identificando e analisando resultados indesejáveis e propondo melhorias. De acordo com Oliveira (2006), a gestão de processos contribui para os sistemas de gestão para a qualidade e é um dos requisitos do Prêmio Nacional da Qualidade.

Uma das contribuições desta pesquisa está na sua aplicabilidade prática e na sua perspectiva social, pois uma Prefeitura é uma organização pública e seus recursos financeiros são provenientes dos cidadãos que pagam impostos. Desse modo, a análise dos processos organizacionais da instituição facilita o planejamento, a liderança e o controle de tudo o que é feito, evitando desperdício do produto do investimento público.

\section{A ADMINISTRAÇÃO PÚBLICA}

A burocracia, discutida por Max Weber através de elementos jurídicos do século XIX, se fundamenta sobre o conhecimento técnico, que lhe concede caráter racional e a transforma em um instrumento assegurador de alta eficiência administrativa. De acordo com Saraiva (2002), o conceito burocrático de Weber, pressupõe um modelo racional guiado por regras formais que padronizam e conferem igualdade no tratamento dos casos. Isso permite uma definição precisa das relações de mando e subordinação na organização, através da distribuição das atividades a serem executadas, mediante suas finalidades.

No entanto, a impessoalidade das normas, ocasionada pela racionalidade dos métodos do modelo burocrático, segundo Saraiva (2002), termina transformando padrões e critérios que deveriam ser descritivos em padrões prescritivos, que não fornecem espaço para a informalidade e o desenvolvimento de noções mais flexíveis de gerenciamento, acabando por desconsiderar, de certa forma, o elemento humano na organização.

Osborne e Gaebler (1994) apontam o surgimento de um novo modelo de gestão que viria gradativamente a substituir tal modelo racional ou burocrático, sistematizado por Weber. Do mesmo modo com que o modelo burocrático se popularizou de acordo com aprofundamento da divisão social do trabalho, esse novo modelo, chamado de gerencialismo, estaria ganhando força em resposta às recentes transformações sociais na execução do trabalho. 
Nesse sentido, Osborne e Gaebler (1994), de modo geral, acreditam que para atender devidamente às demandas do serviço público, as instituições devem desenvolver um papel mais flexível de administração que facilite a melhoria dos seus sistemas de gestão, de modo a desenvolver ações mais efetivas e eficientes em benefício da sociedade. Para Paula (2005) o cerne da administração pública gerencial consiste em qualificar decisões estratégicas, garantir e promover o bom funcionamento dos mercados, assegurar a autonomia e a capacitação gerencial do administrador público e assegurar a democracia por meio da prestação de serviços públicos.

Segundo Biazzi (2007), ao longo das últimas décadas, o setor público tem se visto cada vez mais sob pressão quanto à melhoria de seu desempenho, com a necessidade de demonstrar transparência e avaliação de resultados. Tais fatores resultaram inevitavelmente na busca por melhorias em sua forma de atuação. Paula (2005) afirma que a população tem se encontrado cada vez mais envolvida no processo de redemocratização da administração pública, na tentativa de reformar o Estado e construir um modelo de gestão mais eficaz aberto as suas necessidades. Para a autora, essa mudança de comportamento representa um modelo mais transparente, eficiente economicamente e mais voltado para o interesse e serviços públicos.

Corroborando com esse pensamento, Denhardt (2008) aponta a importância de lidar de maneira inteligente com as organizações públicas, tratando das formas com que o conhecimento pode ser usado em benefício dos problemas da sociedade. Para o autor, as organizações públicas precisam desenvolver um entendimento melhor e mais sistemático de suas atividades, para que correspondam com maior eficiência aos anseios públicos, utilizando o conhecimento adquirido de forma a melhorar a qualidade dos serviços prestados.

Para Silva (1994), as organizações públicas ao enfatizarem tanto o atendimento das necessidades de regulação, prioritárias no modelo burocrático, quanto à prestação dos serviços aos seus clientes ou cidadãos, melhorarão efetivamente a máquina pública. Os incentivos a programas de flexibilização da gestão pública, tornarão a administração mais ágil e receptiva à inovação gerencial, fornecendo maior autonomia e menor custo.

Sendo assim, evidencia-se o interesse na análise das atividades que compõem os serviços públicos destinados à população, objetivo deste artigo, de modo a desencadear um contexto contínuo de renovação pessoal e organizacional no cenário administrativo público, fomentando a inovação e a qualidade nos serviços prestados aos cidadãos.

\section{A GESTÃO DE PROCESSOS}

A estrutura formal de uma organização estabelecida no organograma representa os aspectos básicos aos níveis da definição das tarefas. Entretanto, saber quais as funções que cada pessoa desempenha no interior da estrutura não tem muito sentido sem compreender como essas funções se relacionam umas com as outras. Portanto, para possibilitar uma real avaliação do desempenho das organizações, muitos teóricos organizacionais compreenderam que é preciso saber como as partes estão ligadas, atingindo seus processos.

Assunção e Mendes (2000) salientam que a gestão de processos é capaz de proporcionar mais flexibilidade na gestão da empresa e possibilitar melhores resultados, visto que o foco do modelo está no mercado (ou cliente) e na ênfase nos valores fundamentais de eficiência e eficácia. Estes valores gerenciais estão presentes na gestão por processos, pois dizem respeito a um método que resguarda e persegue a "definição de responsabilidades, a tomada de decisão compartilhada, o agrupamento de atividades e a redução de fluxos" (ASSUNÇÃO; MENDES, 2000, p. 2).

Estas são as condições estabelecidas como primordiais para elevar a capacidade de resposta e melhorar os resultados da organização. Graham e LeBaron (1994 apud GONÇALVES, 2000) afirmam que todo trabalho realizado na empresa que carrega importância, necessariamente, faz parte de algum processo. Com o mesmo pensamento, Gonçalves (2000) afirma não ser possível que uma empresa ofereça um produto ou um serviço sem que o mesmo faça parte de um processo empresarial, da mesma forma que não faz sentido existir um processo empresarial que não ofereça um produto ou um serviço.

Davenport (1994) define processo como um grupo de atividades estruturadas e mensuradas, destinadas à formação de um produto específico para um cliente ou mercado específico, constituindo-se em uma ordenação específica das atividades de trabalho no tempo e no espaço, apresentando um começo e fim, com inputs e outputs claramente identificados. Ainda para Davenport (1994), o processo exige ênfase na maneira como o trabalho é realizado na organização, diferente da ênfase relacionada apenas com o produto em si, centrada apenas no que é produzido e não no processo de produção.

Segundo os critérios de excelência da Fundação Nacional da Qualidade (FNQ), os processos podem ser definidos como um conjunto de atividades estabelecidas que devem ser executadas em uma determinada sequência para conduzir o trabalho a um resultado almejado, assegurando o atendimento às necessidades 
e expectativas dos clientes e demais partes interessadas (FNQ, 2008).

Na visão do Guia para Gerenciamento de Processos de Negócio - BPM CBOK versão 3.0, "processo é uma agregação de atividades e comportamentos executados por humanos ou máquinas para alcançar um ou mais resultados" (ABPMP, 2013, p. 35). Nesse sentido, processos são compostos por atividades que se inter-relacionam de modo a solucionar questões específicas. Tais atividades são gerenciadas por regras de negócio e vistas no contexto de seu relacionamento com outras atividades, fornecendo uma visão de sequência e fluxo do trabalho.

\subsection{Categorias e características dos processos}

Assim como a visão sobre o conceito de processo, diversas são as classificações para os tipos de processos (GONÇALVES, 2000; HRONEC, 1994; ABPMP, 2013), mas todas possuem objetivos semelhantes. Segundo Rummler e Brache (1994), as atividades existentes em qualquer empresa se classificam em três categorias básicas de processos, sendo elas:

a) Processos primários, que são os processos pertencentes à cadeia de valor e são responsáveis pela geração de produtos e serviços que atendem o cliente;

b) Processos auxiliares, que suportam os processos primários do negócio, se preocupando em controlar os recursos para mantê-lo em funcionamento;

c) Processos gerenciais, que regem o funcionamento da empresa, se relacionando com a governança corporativa, estabelecimento de metas e atribuição de orientação e coordenação junto aos outros dois tipos de processos.

Harrington (1993), por seu turno, classifica os processos mediante uma orientação hierárquica, que, segundo ele, facilita o mapeamento dos processos na organização. Os processos e seus componentes podem ser classificados hierarquicamente conforme o Quadro 1.

Quadro 1 - Orientação hierárquica dos processos

\begin{tabular}{|c|l|}
\hline Hierarquia & \multicolumn{1}{c|}{ Descrição } \\
\hline Macroprocesso & $\begin{array}{l}\text { É um processo que geralmente envolve mais de uma função na estrutura organiza- } \\
\text { cional e a sua operação tem um impacto significativo no modo como a organização } \\
\text { funciona. }\end{array}$ \\
\hline Processo & $\begin{array}{l}\text { É um conjunto de atividades conectadas, relacionadas e lógicas que tomam uma en- } \\
\text { trada com um fornecedor, acrescentam valor a este e produzem uma saída para um } \\
\text { consumidor. }\end{array}$ \\
\hline Subprocesso & $\begin{array}{l}\text { É a parte que, relacionada de forma lógica com outro subprocesso, realiza um objetivo } \\
\text { específico em apoio ao macroprocesso e contribui para a missão deste. }\end{array}$ \\
\hline Atividades & $\begin{array}{l}\text { Ocorrem dentro do processo ou subprocesso e são geralmente desempenhadas por } \\
\text { uma unidade (pessoas ou departamento) para produzir um resultado particular. Elas } \\
\text { constituem a maior parte dos fluxogramas. }\end{array}$ \\
\hline Tarefas & $\begin{array}{l}\text { É uma parte específica do trabalho, o menor enfoque do processo, podendo ser um } \\
\text { único elemento ou um subconjunto de uma atividade. Geralmente, estão relaciona- } \\
\text { das a como um item desempenha uma incumbência específica. }\end{array}$ \\
\hline
\end{tabular}

Fonte: Harrington (1993)

Para Trkman (2010), a gestão por processos de negócio consiste no conjunto de esforços de uma organização para analisar e melhorar continuamente atividades importantes para a empresa. Esse tipo de gestão se define como uma prática que integra variadas estratégias e objetivos em uma organização de modo a qualificar atividades para corresponder às necessidades do cliente.

Para o autor, o correto funcionamento da gestão por processos depende de uma visão nítida que integre os objetivos estratégicos e os processos de negócio organizacionais. Ko, Lee e Lee (2009) apontam ainda que a gestão por processos de negócio possui um ciclo de vida e discutem sua importância na compreensão de tal modelo de gestão, conforme retrata o Quadro 2. 
Quadro 2 - Orientação hierárquica dos processos

\begin{tabular}{|c|l|}
\hline Etapa & \multicolumn{1}{|c|}{ Descrição } \\
\hline $\begin{array}{c}\text { Planejamento } \\
\text { e Estratégia }\end{array}$ & $\begin{array}{l}\text { Desenvolve estratégias de melhorias voltadas aos processos atuais e planeja ações de } \\
\text { modificação. }\end{array}$ \\
\hline $\begin{array}{c}\text { Análise dos } \\
\text { Processos de } \\
\text { Negócio }\end{array}$ & $\begin{array}{l}\text { Utiliza metodologias para compreender como se executam os processos atuais em } \\
\text { contraponto às melhorias planejadas. }\end{array}$ \\
\hline $\begin{array}{c}\text { Desenho } \\
\text { (Mapeamento) }\end{array}$ & $\begin{array}{l}\text { Desenha ou mapeia o novo processo de acordo com um modelo que melhor contri- } \\
\text { bua para os objetivos definidos no planejamento. }\end{array}$ \\
\hline $\begin{array}{c}\text { Implementação } \\
\text { do Processo }\end{array}$ & $\begin{array}{l}\text { Coloca em prática o novo modelo de execução do processo para realização de testes } \\
\text { e possíveis ajustes. }\end{array}$ \\
\hline $\begin{array}{c}\text { Controle e } \\
\text { Monitoração }\end{array}$ & $\begin{array}{l}\text { Compara os resultados alcançados com as metas planejadas de modo a obter subsídio } \\
\text { para posteriores tomadas de decisão. }\end{array}$ \\
\hline Refinamento & $\begin{array}{l}\text { Realiza ajustes e melhorias, sempre que necessário, de acordo com os resultados do } \\
\text { controle e monitoramento do processo. }\end{array}$ \\
\hline
\end{tabular}

Fonte: Adaptado de Ko, Lee e Lee (2009)

O mapeamento do processo, como etapa cerne da gestão por processos, de acordo com Harrington (1993), inicia com os objetivos do processo e segue com a decomposição do objetivo em atividades e tarefas. Mapeamento ou modelagem é a atividade de representação que mostra como são realizadas as diversas atividades, desde seu início até alcançar seu objetivo final.

O mapa do processo, conforme defende Harrington (1993), contribui com a melhoria na sua execução, por meio do exame dos relacionamentos de entrada e saída nele representado. A realização do mapa possibilita a identificação dos processos críticos, a definição de oportunidades para melhoria dos processos e a identificação dos pontos desconexos ou ilógicos, quando existentes.

Hronec (1994) reconhece o mapeamento do processo como um recurso gerencial que se traduz na representação visual das atividades para produzir um bem, produto ou serviço. No mesmo sentido, Souza (2003) acredita que o mapeamento de processos deve auxiliar na compreensão, construção, revisão ou melhoria dos mesmos, permitindo seu controle efetivo.

A análise das informações que permeiam toda a cadeia do processo, transferindo informações em todos os elos, é o que antecede o mapeamento do processo, visto que não é possível compreender o resultado dos produtos e serviços sem antes compreender como se dá o fluxo das atividades e como as informações se comportam no processo.

\subsection{A gestão da informação nos processos organizacionais}

Vital, Floriani e Varvakis (2010) destacam os fluxos de informação nos processos organizacionais, sublinhando que uma das funções da informação é fornecer subsídios aos gestores para tomar decisões. Barreto (1999) salienta que os fluxos de informação podem ser observados sob duas óticas: da tecnologia da informação e a da ciência da informação. Em relação à tecnologia, os fluxos são destinados a possibilitar o acesso à informação da melhor maneira, enquanto que, na ciência da informação, eles interferem na qualificação da competência dos usuários, visando à compreensão dos conteúdos de informação.

Seguindo nessas mesmas considerações, Ferreira e Perucchi (2011) evidenciam que o fluxo atende ao fenômeno da transferência de informação de um emissor para um receptor e, por isso, a informação deve possuir um valor associado às necessidades do receptor e ao interesse do emissor em compartilhar tal informação. No mesmo sentido, para McGee e Prusak (1994), o valor da informação é determinado pelo usuário, querendo com isso dizer que, para ser útil, a informação depende da análise realizada pelo mesmo, conforme sua necessidade ou circunstância de aplicação. Para McGee e Prusak (1994), a criação, captação, organização, distribuição e uso da informação são aspectos a serem considerados pelas organizações preocupadas com a gestão de processos.

\section{PROCEDIMENTOS METODOLÓGICOS}

Este estudo se guiou nas diretrizes do Business Process Management (BPM), ou gestão por processos de negócios. Os modelos de BPM fornecem subsídio para a identificação, mapeamento e detalhamento dos 
processos em uma organização, bem como, em situações mais complexas, asseguram ainda a execução, administração, supervisão e controle sobre os mesmos.

Sendo assim, o Guia para Gerenciamento de Processos de Negócio - BPM CBOK versão 3.0, elaborado pela Association of Business Process Management Professionals (ABPMP), serviu de referência para a análise dos processos organizacionais apresentados neste estudo de caso. No mais, o software Bizagi Process Modeler foi o aplicativo usado na modelagem dos processos. O Bizagi possibilita criar e visualizar diagramas, modelos e documentações de processos de negócio através de elementos adaptados da notação Business Process Model and Notation (BPMN), um formato mundialmente aceito em modelagem de processos.

A análise do processo se utilizou da elaboração de dois cenários: o primeiro, denominado "AS IS", caracteriza o processo como ele ocorre atualmente; o segundo, denominado "TO BE", caracteriza um cenário ideal com melhoria no desempenho, considerando o tempo de realização do processo e o comprometimento de recursos humanos. As melhorias foram propostas com base na comparação do cenário "AS IS" com o cenário "TO BE", simulando o desempenho do processo em função das variáveis de tempo e os recursos humanos envolvidos, em um ciclo completo de execução.

A análise e a melhoria também contaram com observações diretas de um dos pesquisadores, sendo que o mesmo faz parte da equipe que atua na execução dos processos seletivos simplificados.

\subsection{Delineamento da pesquisa}

O objeto de estudo desta pesquisa consistiu na análise das etapas que compõem os processos seletivos simplificados de uma Prefeitura pertencente à Região Metropolitana do Recife, assim como das pessoas envolvidas na sua execução, cujo acompanhamento ocorreu no período de outubro a novembro de 2014.

De acordo com as categorizações de processos já apresentadas, os processos seletivos simplificados, objeto deste estudo, se caracterizam como processos estratégicos na esfera de atuação da Prefeitura, pois estão ligados diretamente às suas atividades fim, relativos à contratação e à gestão de pessoal capacitado para atender às demandas do município.

A escolha do referido processo para análise foi realizada com base na sua importância, visto que a contratação por processos seletivos simplificados é uma atividade que permite à população acesso a emprego em órgãos e instituições públicas de maneira ampla e democrática.

Por ser um procedimento que deve assegurar igualdade de oportunidades a todos interessados, o mesmo precisa ser aplicado da melhor maneira possível, identificando e selecionando os candidatos mais adequados mediante critérios objetivos. Soma-se a isso a importância dos servidores públicos na manutenção das atividades do município, cujas ações refletirão diretamente na sociedade.

Outro critério diz respeito à eficiência nas despesas públicas e do serviço público. Além de primar pela transparência e legalidade dos processos, os mesmos devem ser realizados em tempo hábil, sem ocorrência de erros.

\section{APRESENTAÇÃO DOS RESULTADOS}

A análise e seus respectivos resultados estão apresentados conforme as recomendações para documentação e modelagem do processo estabelecidas pela ABPMP (2013).

\subsection{Fluxograma do processo}

A modelagem do processo objetiva representá-lo de forma precisa e completa, caracterizando seu funcionamento, de modo a melhorar sua capacidade de resposta, como afirma ABPMP (2013).

Nos processos seletivos simplificados da Prefeitura as atividades estão a cargo da Coordenação de Cadastro e Movimentação de Pessoas (CCMP), pertencente à Gerência de Administração de Pessoas (GAP), um setor específico da Secretaria Executiva de Formação e Gestão de Pessoas (SEFOGEP), que hierarquicamente está subordinada à Secretaria Municipal de Planejamento, Gestão e Desenvolvimento Econômico (SEPLAG) do município em questão.

Os processos seletivos simplificados envolvem a participação de três grandes áreas, cada qual com atividades específicas. Desse conjunto de atividades apenas três podem ser realizadas simultaneamente, sendo uma relacionada à Secretaria para a qual as vagas se destinam, compreendendo a análise da documentação e as outras relacionadas à CCMP, incluindo a inserção das notas dos candidatos no sistema e posterior convocação dos mesmos. Todas as atividades contam com a participação da CCMP, direta ou indiretamente.

Os processos seletivos simplificados analisados neste trabalho, estão regulamentados pelo artigo 37 da Constituição Federal de 1988 que trata dos cargos, empregos e funções públicas e pela Lei Municipal no 099/2001, que estabelece os casos de contratação por tempo determinado para atender necessidade 
temporária de excepcional interesse público. A Figura 1 ilustra o fluxograma completo da sequência de atividades realizadas no processo.

Figura 1 - Fluxo dos processos seletivos simplificados

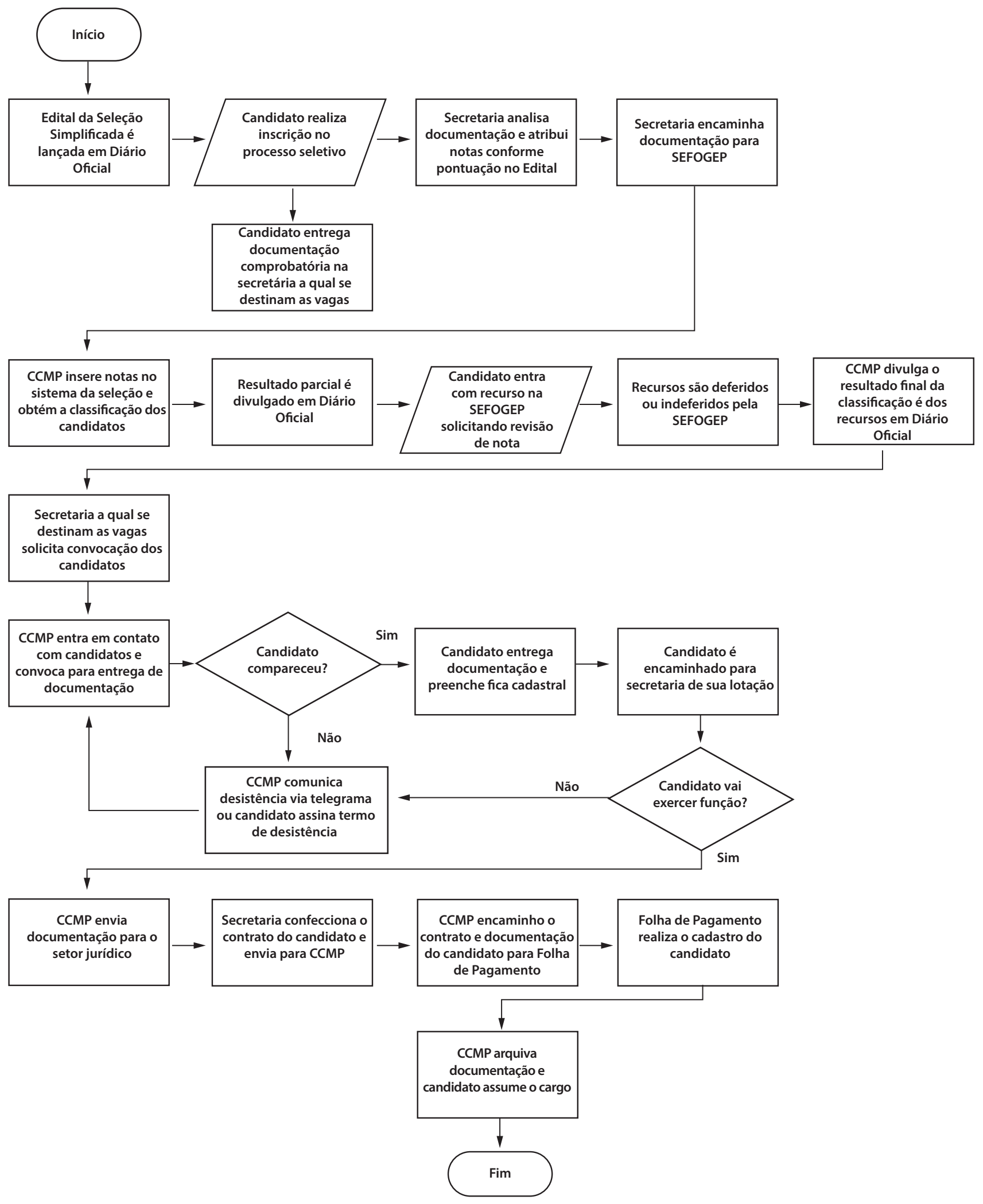

Fonte: Elaborado pelos autores, com base nos resultados da pesquisa (2014). 
O fluxograma, como se vê na Figura 1, é uma apresentação esquemática do processo, representada por símbolos, além de textos elucidativos, demonstrando a tramitação do fluxo de trabalho. Tanto os textos como os símbolos são dispostos no esquema de acordo com certas regras de uso generalizado (CURY, 2000). Os símbolos utilizados no fluxograma indicam a origem, o processamento e o destino da informação.

\subsection{A modelagem do processo}

O tempo de realização de cada atividade do cenário "AS IS" pode ser visualizado no Quadro 3, de modo a completar todo o processo seletivo simplificado, considerando, neste caso, que apenas um candidato seja convocado. O quadro foi composto através de uma média do tempo de cada atividade, considerando desde a análise dos cronogramas dos Editais das sete Seleções Públicas Simplificadas que ocorreram no ano de 2014 (Totalizando 1.868 inscritos), até a inserção em Folha de Pagamento do primeiro candidato classificado de cada seleção.

Quadro 3 - Tempo de execução do processo "AS IS"

\begin{tabular}{|c|c|}
\hline Período de Atividade & Tempo \\
\hline 1. Lançamento do Edital & 1 dia \\
\hline 2. Inscrição no processo seletivo & 5 dias \\
\hline 3. Entrega de documentação comprobatória & 5 dias \\
\hline 4. Análise de documentação e atribuição de notas & 10 dias \\
\hline 5. Inserção de notas no sistema & 2 dias \\
\hline 6. Armazenagem da documentação & - \\
\hline 7. Divulgação do resultado parcial & - \\
\hline 8. Recebimento de recursos & 3 dias \\
\hline 9. Divulgação do resultado final & - \\
\hline 10. Solicitação de convocação do candidato & - \\
\hline 11. Convocação do candidato & 3 dias \\
\hline \multicolumn{2}{|l|}{$\begin{array}{l}\text { Observação: Esta etapa pode variar de acordo com a quantidade de candidatos convo- } \\
\text { cados em cada chamada. Em suma, cada candidato tem até } 3 \text { dias úteis para se apre- } \\
\text { sentar. Nesse sentido, o processo pode se prolongar nos casos em que o candidato } \\
\text { confirma a intenção de assumir a vaga, mas não comparece na data de apresentação, } \\
\text { desistindo do processo seletivo. }\end{array}$} \\
\hline 12. Lotação do candidato & - \\
\hline 13. Confecção de contrato do candidato & 3 dias \\
\hline \multicolumn{2}{|l|}{$\begin{array}{l}\text { Observação: Esta etapa varia drasticamente devido às demandas externas aos proces- } \\
\text { sos seletivos. Atualmente, por ser uma etapa executada pelos departamentos jurídicos } \\
\text { das Secretarias interessadas, o tempo pode ser muito maior, considerando a quantida- } \\
\text { de de candidatos convocados e possíveis atrasos inerentes às demais funções realizadas } \\
\text { pelos colaboradores desses departamentos. }\end{array}$} \\
\hline 14. Cadastro do candidato em Folha de Pagamento & $1 \mathrm{dia}$ \\
\hline Total & 33 dias \\
\hline
\end{tabular}

Fonte: Elaborado pelos autores, com base nos resultados da pesquisa (2014). 
O Quadro 5 mostra o mapeamento do processo com suas características atuais. A Figura 2 ilustra o processo modelado de acordo com o cenário "AS IS" e de acordo com cada atividade descrita.

Figura 2 - Mapeamento do processo de seleções simplificadas "TO BE"

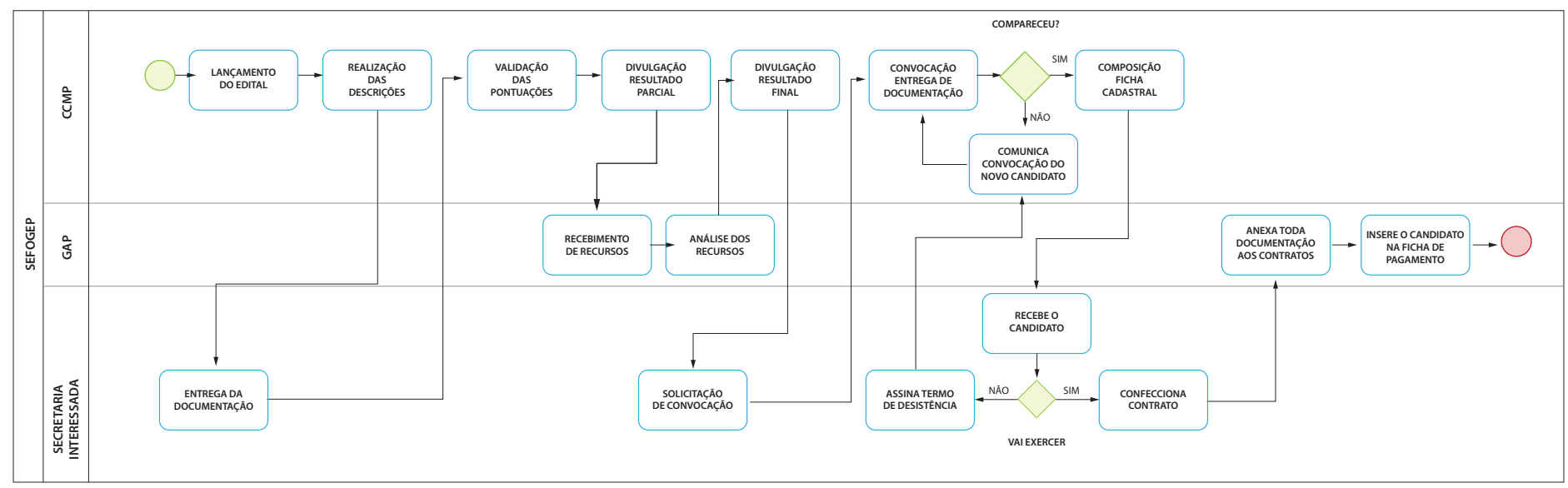

Fonte: Elaborado pelos autores, com base nos resultados da pesquisa (2014).

Nas circunstâncias atuais, conforme ilustra o cenário, o ciclo completo do processo de seleção simplificada consome 33 dias, ou seja, mais de um mês até a convocação dos candidatos aprovados.

Levando em consideração o resultado das observações na execução das atividades, foram propostas melhorias de desempenho no desenvolvimento do processo, na perspectiva da melhoria do fluxo da informação. A observação direta permitiu documentar detalhes do processo atual, revelando atividades e tarefas que, de outra forma, poderiam não ser reconhecidas, devido à inexistência de um regimento interno que regulamente as etapas do processo. Aliada a observação direta, a execução do aplicativo Bizagi permitiu a identificação de variações e desvios que ocorrem no dia a dia do trabalho. Nesse sentido, as propostas foram compostas de acordo com o Quadro 4.

Quadro 4 - Propostas de melhorias para o cenário atual do processo

\begin{tabular}{|c|c|c|}
\hline Melhoria & \multicolumn{1}{c|}{ Proposta } \\
\hline $\begin{array}{c}\text { Quanto aos } \\
\text { Editais }\end{array}$ & $\begin{array}{c}\text { Os Editais dos processos seletivos simplificados possuem as mesmas característi- } \\
\text { cas quanto às suas regulamentações e legislações. O que muda de uma seleção para } \\
\text { outra são as especificações dos cargos a serem contratados e, em raros casos, critérios } \\
\text { de pontuação, quando a função requer especificidades quanto ao seu ofício. } \\
\text { Nesse sentido, a elaboração de um modelo de Edital em formato de mala direta, } \\
\text { com campos que especificam diretamente o que muda de uma seleção para a outra, } \\
\text { certamente diminuirá o tempo de lançamento do Edital em Diário Oficial e evitará } \\
\text { erratas por possíveis campos que passem despercebidos pela conferência manual. }\end{array}$ \\
\hline $\begin{array}{c}\text { Atualmente, após realizar a inscrição pelo sistema do processo seletivo, o can- } \\
\text { sistema } \\
\text { de inscrição }\end{array}$ & $\begin{array}{l}\text { didato deverá, em uma etapa posterior, apresentar em envelope lacrado toda a sua } \\
\text { documentação comprobatória. Essa documentação será conferida manualmente pela } \\
\text { Secretaria interessada, o que é uma atividade extremamente dispendiosa para quem } \\
\text { analisa a documentação. } \\
\text { Muitos candidatos entregam os documentos de qualquer jeito e os colaborado- } \\
\text { res necessitam organizar folha por folha de modo a identificar que documento com- } \\
\text { prova qual informação prestada na inscrição. Em outros casos, os candidatos sequer } \\
\text { fornecem a documentação comprovando as informações prestadas, apenas desperdi- } \\
\text { çando o tempo do colaborador e atrasando a divulgação do resultado. } \\
\text { Nesse sentido, um sistema de inscrição que permita o carregamento da docu- } \\
\text { mentação comprobatória em formato digital já no ato da inscrição não só eliminará } \\
\text { um passo do processo, como diminuirá drasticamente o tempo de conferência da do- } \\
\text { cumentação e atribuição das notas, bastando apenas que o candidato apresente os } \\
\text { documentos originais quando convocado. }\end{array}$ \\
\hline
\end{tabular}




\begin{tabular}{|c|c|}
\hline $\begin{array}{c}\text { Quanto à } \\
\text { conferência da } \\
\text { documentação }\end{array}$ & $\begin{array}{l}\text { Levando em consideração que o sistema de inscrição fornecerá a documenta- } \\
\text { ção comprobatória do candidato, os próprios colaboradores da Secretaria interessada } \\
\text { podem inserir as notas no sistema, cabendo à CCMP apenas a validação e verificação } \\
\text { de possíveis erros ou falhas, de acordo com os requisitos do Edital, nas pontuaçôes } \\
\text { lançadas. }\end{array}$ \\
\hline $\begin{array}{c}\text { Quanto ao } \\
\text { armazenamento } \\
\text { dos documentos }\end{array}$ & $\begin{array}{l}\text { O arquivo fica disponível em rede e não é mais preciso que diversos armários } \\
\text { sejam ocupados com o armazenamento dos documentos, economizando recursos e } \\
\text { tempo quando se fizer necessária a localização da pasta de algum candidato. }\end{array}$ \\
\hline $\begin{array}{c}\text { Quanto à } \\
\text { convocação } \\
\text { dos candidatos }\end{array}$ & $\begin{array}{l}\text { Levando em consideração que o sistema de inscrição fornecerá toda a documen- } \\
\text { tação e informaçães do candidato, não seria mais preciso perder tempo localizando a } \\
\text { pasta de cada candidato, assim como o mesmo não precisaria mais apresentar toda } \\
\text { a documentação já fornecida, como ocorre no processo atual. Caberia ao candidato } \\
\text { apenas trazer os documentos originais para comprovação. O próprio sistema geraria } \\
\text { a Ficha Cadastral devidamente preenchida, com toda a documentação necessária e } \\
\text { pronta para impressão e encaminhamento à Folha de Pagamento. }\end{array}$ \\
\hline $\begin{array}{l}\text { Quanto à } \\
\text { inserção do } \\
\text { candidato } \\
\text { na Folha de } \\
\text { Pagamento }\end{array}$ & $\begin{array}{l}\text { As Secretarias que solicitam a contratação dos candidatos possuem demandas } \\
\text { externas aos trâmites do processo seletivo e muitas vezes não estão preparadas para } \\
\text { suprir a demanda da confecção de contratos. Isso atrasa a inserção do candidato na } \\
\text { Folha de Pagamento e acarreta no atraso de pagamento do funcionário, que muitas } \\
\text { vezes já iniciou o exercício. } \\
\text { A confecçãa do contrato atualmente acaba se tornando uma barreira desneces- } \\
\text { sária, visto que os termos e cláusulas contratuais são padronizados para qualquer pro- } \\
\text { cesso seletivo simplificado na Prefeitura. Nesse sentido, um módulo no sistema que } \\
\text { permita gerar o contrato do candidato, da mesma forma que seria a composição da } \\
\text { Ficha Cadastral, economizará tempo na confecção manual dos contratos, eliminará } \\
\text { possíveis erros ou falhas nessa confecção e não mais atrasará a inserção do candidato } \\
\text { na Folha de Pagamento. }\end{array}$ \\
\hline $\begin{array}{l}\text { Quanto ao } \\
\text { monitoramento } \\
\text { do processo }\end{array}$ & $\begin{array}{l}\text { Por fim, as três grandes áreas no processo teriam um sistema que facilitaria e } \\
\text { permitiria a localização, a qualquer momento, dos documentos, contratos e qualquer } \\
\text { outra informação sobre o candidato. Além disso, cada área poderia visualizar em qual } \\
\text { etapa se encontra o processo, podendo cobrar do setor específico o adiantamento das } \\
\text { atividades, evitando gargalos. }\end{array}$ \\
\hline
\end{tabular}

Fonte: Elaborado pelos autores, com base nos resultados da pesquisa (2014).

Com a aplicação das melhorias propostas, o tempo de realização de cada atividade pode ser visualizado no Quadro 5, que apresenta uma estimativa justificada do tempo relativo a cada atividade de modo a completar todo o processo seletivo simplificado, levando em consideração que apenas um candidato seja convocado.

Quadro 5 - Tempo de execução do processo "TO BE"

\begin{tabular}{|l|c|}
\hline \multicolumn{1}{|c|}{ Período de Atividade } & Tempo \\
\hline 1. Lançamento do Edital & 1 dia \\
\hline 2. Inscrição no processo seletivo & 10 dias \\
\hline $\begin{array}{l}\text { Justificativa: A etapa de “Entrega de documentação comprobatória” composta por } \\
\text { cinco dias é eliminada com a utilização do sistema, no entanto, a etapa de "Inscrição } \\
\text { no processo seletivo" é elevada, tendo em vista a necessidade de carregamento das } \\
\text { documentações comprobatórias no sistema por parte dos candidatos. }\end{array}$ & \\
\hline 3. Análise de documentação e inserção de notas no sistema & 2 dias \\
\hline
\end{tabular}




\begin{tabular}{|l|c|}
\hline $\begin{array}{l}\text { Justificativa: As etapas de “Análise de documentação" e "Inserção de Notas", que } \\
\text { somavam doze dias, são mescladas e reduzidas drasticamente com a utilização do } \\
\text { sistema, visto que os colaboradores não precisariam mais conferir a documentação } \\
\text { manualmente, precisando filtrá-las uma por uma em cada envelope. No sistema, os } \\
\text { colaboradores veriam diretamente a cópia do documento correspondente a cada } \\
\text { informação prestada pelo candidato na inscrição, podendo inserir de imediato a nota } \\
\text { do candidato no sistema. }\end{array}$ & \\
\hline 4. Validação de notas e divulgação do resultado parcial & \\
\hline $\begin{array}{l}\text { Justificativa: É acrescentado um dia para que a equipe da CCMP verifique se todos os } \\
\text { candidatos receberam as notas devidamente, de modo a evitar que algum candidato } \\
\text { tenha passado despercebido erroneamente durante a inserção de notas no sistema. }\end{array}$ & \\
\hline 5. Recebimento de recursos & 1 dia \\
\hline 6. Divulgação do resultado final & 3 dias \\
\hline 7. Solicitação de convocação do candidato & - \\
\hline 8. Convocação do candidato & - \\
\hline 9. Lotação do candidato & 3 dias \\
\hline 10. Confecção de contrato do candidato & - \\
\hline $\begin{array}{l}\text { Justificativa: Com a utilização do sistema, os contratos poderiam ser gerados automati- } \\
\text { camente, através dos dados informados pelos candidatos na inscrição e termos padrões } \\
\text { referentes a cada seleção, bastando apenas uma simples configuração dessa ferramen- } \\
\text { ta no sistema. Essa ferramenta eliminaria qualquer perda de tempo e possíveis erros de } \\
\text { digitação relativos à confecção manual dos contratos. }\end{array}$ & 1 dia \\
\hline $\begin{array}{l}\text { 11. Cadastro do candidato em Folha de Pagamento } \\
\text { Total }\end{array}$ & 1 dia \\
\hline
\end{tabular}

Fonte: Elaborado pelos autores, com base nos resultados da pesquisa (2014).

A Figura 3 ilustra o processo modelado de acordo com o cenário "TO BE", após realizados os ajustes decorrentes das propostas de melhoria, não descumprindo prazos legais previstos na legislação anteriormente citada.

Figura 3 - Mapeamento do processo de seleções simplificadas "TO BE"

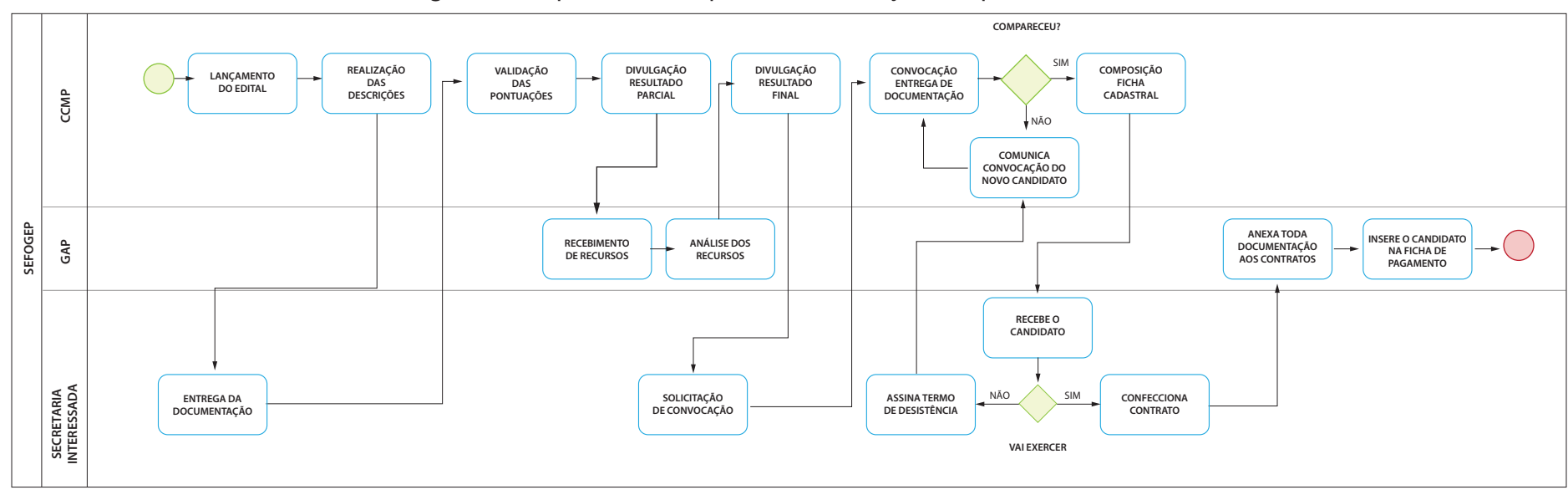

Fonte: Elaborado pelos autores, com base nos resultados da pesquisa (2014).

Nas circunstâncias idealizadas, conforme ilustra o cenário "TO BE", o ciclo completo do processo de seleção simplificada passa a consumir 22 dias, ou seja, menos de um mês até a convocação dos candidatos aprovados. 


\subsection{Comparação dos cenários}

A partir da modelagem dos cenários foi possível comparar o desempenho das duas situações ("AS IS" x "TO BE"), e em uma perspectiva racional identificar aspectos que podem ser otimizados para um melhor rendimento dos processos. Do ponto de vista do BPM, significa realizar a execução dos processos com a mesma demanda, mas em menos tempo e com o uso de menos recursos.

O primeiro aspecto que visualmente se percebe ao comparar os cenários é a quantidade de atividades do processo. No cenário "AS IS" são 14 atividades, já o cenário "TO BE" apresenta 11 atividades, o que representa uma redução na ordem de aproximadamente $21 \%$. Nesse sentido, dois fatores são fundamentais para a implementação plena do cenário "TO BE":

a) A criação do novo sistema ou atualização com cobertura dos pontos negativos do sistema atual, assim como sua utilização em todo potencial;

b) A modificação nas políticas internas da instituição, de modo a agilizar a demanda das convocações e inserções dos candidatos na Folha de Pagamento.

Embora a melhoria dos processos se paute na utilização de tecnologias, o elemento humano é quem o realiza em todas as atividades para atender às diversas demandas que incidem sobre esse processo, da publicação dos resultados à convocação dos candidatos.

O cenário "AS IS" apresenta o comprometimento de três grandes áreas para a realização dos processos, sendo a CCMP, GAP e Secretaria interessada. Com a modelagem do cenário "TO BE" o processo foi racionalizado, liberando parte dos recursos humanos envolvidos externamente à CCMP. É possível observar essa racionalização do tempo na comparação dos cenários (AS IS x TO BE) conforme ilustra o Gráfico 1.

Gráfico 1 - Comparação do tempo nos cenários dos processos

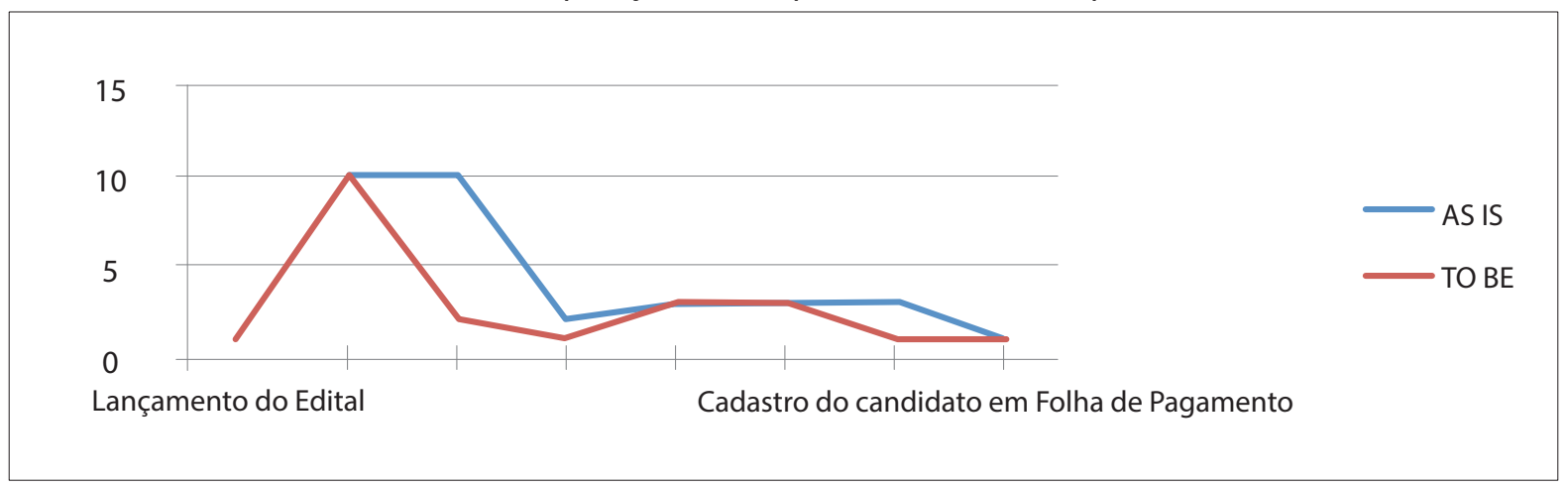

Fonte: Elaborado pelos autores, com base nos resultados da pesquisa (2014).

No cenário "TO BE" obtém-se uma diminuição de aproximadamente $33 \%$ do tempo de execução dos processos seletivos simplificados, o que significa menos 11 dias na realização de um ciclo completo.

\section{CONCLUSÃO}

O presente estudo se caracterizou na análise dos processos seletivos simplificados realizados por uma Prefeitura, focando na identificação de melhorias na execução de suas atividades. A partir da construção dos cenários "AS IS" e "TO BE", foi possível compreender como o processo funciona atualmente (cenário AS IS), o que permitiu sua reestruturação em um cenário desejado (TO BE), visando melhor desempenho, considerando aspectos como eliminação de atividades que atrasavam o desenvolvimento do processo, permitindo uma melhor distribuição do tempo empregado na sua execução e melhor alocação dos recursos humanos envolvidos.

Esse mérito ocorreu devido à utilização de uma análise racional instrumental quanto à comparação dos cenários modelados dos processos seletivos simplificados, principalmente no que diz respeito aos aspectos técnicos relacionados a um melhor aproveitamento de um sistema mais voltado às necessidades dos envolvidos com a execução do processo. Essa nova abordagem permitiu vislumbrar a possibilidade de um incremento nos resultados do processo, obtendo os mesmos índices de saídas, mas com uma redução significante dos recursos utilizados e do tempo de execução.

O processo modelado permite o desenvolvimento do novo sistema voltado para a BPM, que acarretará 
impactos na qualidade e no desempenho dos processos seletivos simplificados, visto que o aumento na demanda das convocações tornaria o processo muito dispendioso, se continuado da forma em que se encontra atualmente.

Entretanto, este foi apenas o primeiro passo nas melhorias que este trabalho propõe. Mesmo que o mapeamento do processo subsidie consideravelmente o desenvolvimento de um sistema, ainda há muito trabalho a ser realizado. Aspectos técnicos como o estabelecimento da base de dados e das inter-relações entre as classes demandam novos estudos para o redesenho de toda interface do sistema. Além disso, o novo sistema deverá passar por diversos testes, através de simulações realistas, antes de sua implementação. Contudo, essas etapas futuras serão mais facilmente realizadas no tocante ao desenvolvimento do sistema, uma vez que todo o estudo do processo e do usuário envolvido com o mesmo já fora conduzido a partir da sua análise e propostas de melhorias.

No mais, a partir deste estudo, novas oportunidades se evidenciam sob a perspectiva da racionalização dos processos organizacionais, visto que os desdobramentos dos processos seletivos simplificados acarretam também na análise direta dos recursos financeiros envolvidos, a aquisição de um novo sistema de informação ou até na ampliação do quadro funcional de colaboradores do processo, sempre com o intuito de aperfeiçoar o serviço prestado ao cidadão, cliente direto e indireto de toda e qualquer ação voltada para a administração pública.

\title{
PROCESS MANAGEMENT IN THE ANALYSIS OF SIMPLIFIED PUBLIC SELECTIONS: CASE STUDY ON A CITY HALL
}

\begin{abstract}
This is a case study whose objective was to map and analyze organizational processes with the objective of making the public service more responsive, efficient and focused on the user. The study object was the process of the simplified public selections made by a municipality, observed according to theory of information flow. Data collection combined direct observation and monitoring of the process from October to November 2014, and the representation of the information flow and the description of the elements used the Bizagi Modeler application. Simplified selection processes were scaled on performance levels and the study found that it is possible to decide more objectively in relation to the sequence of activities, distribution of work and the time planned for its execution.
\end{abstract}

Keywords: Process Management. Information Flow. Information Management.

\section{REFERÊNCIAS}

ASSOCIATION OF BUSINESS PROCESS MANAGEMENT PROFESSIONALS (ABPMP). BPM CBOK V3.0: Guia para o Gerenciamento de Processos de Negócio Corpo Comum de Conhecimento. Brasil: ABPMP, 2013.

ASSUNÇÃO, Maria Aparecida de; MENDES, Paule Jeanne Vieira. Mudança e gestão de processo em organização pública. In: Congresso Internacional Del CLAD sobre La Reforma Del Estado y de La Administración Pública, 5., 2000, Santo Domingo. Anais do V Congresso Internacional Del CLAD sobre La Reforma Del Estado y de La Administración Pública. Santo Domingo: CLAD, 2000. p. 01-14.

BARRETO, Aldo de Albuquerque. Os destinos da ciência da informação: entre o cristal e a chama. DataGramaZero: Revista de Ciência da Informação, Rio de Janeiro, n. 0, dez. 1999.

BIAZZI, Monica Rottmann de. Instituições públicas de ensino superior: estudo de casos de aperfeiçoamento de processos administrativos. 2007. Dissertação (Mestrado) - Universidade de São Paulo, São Paulo.

CURY, Antonio. Organização e métodos: uma visão holística. 7. ed. São Paulo: Atlas, 2000.

DAVENPORT, Thomas Hayes. Reengenharia de processos: como inovar na empresa através da Tecnologia da Informação. 2. ed. Rio de Janeiro: Campus, 1994.

DENHARDT, Robert B. Teoria Geral da Administração Pública. 5. ed. Tradução de Francisco Heidemann. Florianópolis: ESAG/UDESC, 2008. 
FERREIRA, Tereza Evâny de Lima Rênor; PERUCCHI, Valmira. Gestão e o Fluxo da Informação nas Organizações: A Informação no Contexto Organizacional. Revista ACB: Biblioteconomia em Santa Catarina, Florianópolis, n. 2, p. 446-463, jul./dez. 2011.

FUNDAÇÃO NACIONAL DA QUALIDADE (FNQ). Cadernos Rumo à Excelência: Processos. São Paulo: FNQ, 2008.

GONÇALVES, José Ernesto Lima. As empresas são grandes coleções de processos. RAE - Revista de Administração de Empresas, São Paulo, n. 1, p. 6-19, jan./mar. 2000.

HARRINGTON, James. Aperfeiçoando Processos Empresariais. São Paulo: Makron Books, 1993.

HRONEC, Steven. Sinais Vitais: usando medidas do desempenho da qualidade, tempo e custo para traçar a rota para o futuro de sua empresa. São Paulo: Makron Books, 1994.

KO, Ryan; LEE, Stephen; LEE, Eng Wah. Business process management (BPM) standards: a survey. Business Process Management Journal, v. 15, n. 5, p. 744-791, 2009.

MCGEE, James; PRUSAK, Laurence. Gerenciamento estratégico da informação. Rio de Janeiro: Campus, 1994.

OLIVEIRA, Saulo Barbará de. Gestão por processos: Fundamentos, técnicas e modelos de implementação: foco no sistema de gestão da qualidade com base na ISO 9000:2000. Rio de Janeiro: Qualitymark, 2006.

OSBORNE, David; GAEBLER, Ted. Reinventando o governo: como o espírito empreendedor está transformando o setor público. Brasília: MH Comunicação, 1994.

PAULA, Ana Paula Paes de. Por uma nova gestão pública: limites e potencialidades da experiência contemporânea. Rio de Janeiro: FGV, 2005.

RUMMLER, Geary; BRACHE, Alan. Melhores Desempenhos das Empresas: uma abordagem prática para transformar as organizações através da reengenharia. 2. ed. São Paulo: Makron Books, 1994.

SARAIVA, L. A. S. Cultura organizacional em ambiente burocrático. Revista de Administração Contemporânea, Rio de Janeiro, v. 6, n. 1, p. 187-207, 2002.

SILVA, Carlos Eduardo de Souza e. Autonomia de gestão e concorrência: em busca de novas formas de gestão do setor público em um contexto pós-fordista. Revista de Administração Pública, Rio de Janeiro, v. 28, n. 3, p. 211-228, out./dez. 1994.

SOUZA, Solange Evangelista de. Um estudo de caso para estabelecer a estrutura de informação associada à competitividade do negócio de uma empresa atuante no mercado de trânsito. 2003. Tese (Doutorado) - Universidade Federal de Pernambuco, Recife.

TRKMAN, Peter. The Critical Success Factors of Business Process Management. International Journal of Information Management, v. 30, p. 125-134, 2010.

VITAL, Luciane Paula; FLORIANI, Vivian Mengarda; VARVAKIS, Gregório. Gerenciamento do fluxo de informação como suporte ao processo de tomada de decisão. Informação \& Informação, Londrina, n. 1, p. 85-103, jan./jun. 2010. 